\title{
Eoin Coleman (Oren Kolman) 1959 - 2015
}

Eoin Coleman, who died on December 4th 2015, was well known to many members of the IMS, either personally or via the interesting articles he published in this Bulletin over a number of years, $[1,2,3,4,5,7,8]$. Eoin had converted to Judaism some 35 years ago and later was widely known in mathematical circles as Oren Kolman. I will refer to him as Eoin/Oren throughout.

Eoin/Oren attended St. Gerards School in Bray and then Glenstal Abbey before commencing his university career in UCD. He was a gifted child, excelling at whatever he turned his hand to. Academically he was interested in mathematics and languages but was also an accomplished pianist, particularly liking Rachmaninov. His sister Orla recounts that he learned to type at the age of 3! In 1980 he graduated with a first-class honours BA in Mathematics and Philosophy and subsequently completed in 1986 a first-class honours MA in Mathematics under the supervision of Seán Dineen on the topic "Ultraproducts of Banach Spaces"; he had spent some of the intervening years travelling and working in a Kibbutz in Israel.

In 1987 Eoin/Oren held a teaching assistantship at the Hebrew University of Jerusalem working with the renowned logician Saharon Shelah with whom he went on to complete several research papers $[6,9,10,12]$. Although he learned a lot about set theory and model theory, Eoin/Oren was not totally happy with his experience there and decided not to submit a doctoral thesis even though encouraged to do so. For this and other personal reasons he decided to return to Dublin in 1991 and taught at both UCD and DIT. He was an active participant in my seminar on Abelian Groups during that time.

Eoin/Oren's other great passion was music and in the late 1990s he decided to take a "break" from mathematics and study music. He moved to Kings College, London where he completed the degrees M.Mus(Historical Musicology) in 1997 and Ph.D(Musicology) in 2003. I deliberately put the word "break" in quotes since somehow he continued to publish interesting mathematical research while studying music - see $[8,9,10,11,12]$. He also produced at least one paper relating to his work in music, [13]. 
After this musical excursion, Eoin/Oren spent some time working in Banking and Economics in France; he entertained many of us with his stories of his discussions with Nobel Prize Winners in Economics during this time!

Eoin/Oren then decided to return full time to mathematics and, despite having a larger publication list than many post-doctoral colleagues, he started afresh doing research with Pierre Matet at the University of Caen. His thesis "Logical Aspects of Slender Groups" was a masterly and deep analysis of the model-theoretic, set-theoretic and logical properties of slender groups. (A brief introduction to this class of groups may be found in his paper in this Bulletin, [8].) He received his doctorate in 2009 and I have been informed that the doctoral committee thought it worthy of a habilitation thesis, but it was not technically possible to make such an award. (I believe there was a possibility that his thesis would appear as a book but I have been unable to find out what happened in this regard.)

Although I had known Eoin/Oren since his time in DIT (1991-94), it was during the period from 2005 onwards that I got to know him well. We collaborated on two research papers, $[14,16]$ and it was a joy to work with him. He was precise and demanded full rigorous arguments for all details. During this period he had a number of teaching positions: University of East Anglia, University of Bedfordshire and a part-time position in Cambridge. His interaction with students in these teaching posts was tremendous. Let me quote from a colleague of his at East Anglia:

The students are raving about him, he is inventive, interesting and enthusiastic. He gets things done that others cannot. He is brilliant, both as a teacher of say first year geometry and as a presenter at a research seminar. At admissions days he gives talks to prospective students about interesting mathematics and these talks are really excellently prepared and received.

My last interaction with him was a few weeks before his sudden death when he asked me to act as a referee for him in his application for senior membership of Hughes College, Cambridge; following interview, his application was successful and he was delighted to have a firmer connection to Cambridge. His Part III lectures on Topics in Set Theory had been very well received there the previous year. 
On a personal level, Eoin/Oren was wonderful company: a firstrate intellect, well informed about so many issues, a fluent speaker of many languages and an interested, and interesting, hill walker. He was intensely private and chose a somewhat solitary life, close to nature planting trees and honouring Jewish traditions. He had an enduring love affair with France, having had for many years a home in Calvedos and more recently in the Auvergne; he travelled to France every few weeks. His wry sense of humour was always a pleasure to encounter. In many ways he was a real renaissance man and will be sadly missed by so many in the mathematical community world-wide.

Ar dheis Dé go raibh a anam dílis.

Acknowledgements. The author wishes to acknowledge the help and input of Orla Coleman and Pauline Mellon.

\section{PUBLICATIONS}

[1] Banach space ultraproducts. Irish Math. Soc. Bull. No. 18 (1987), 3039.

[2] Perfect compact $T_{1}$ spaces. Irish Math. Soc. Bull. No. 26 (1991), 5258.

[3] Internal forcing axioms: Martin's axiom and the proper forcing axiom. Irish Math. Soc. Bull. No. 29 (1992), 3148.

[4] Non-measurable sets and translation invariance. Irish Math. Soc. Bull. No. 34 (1995), 2225.

[5] Jonsson groups, rings and algebras. Irish Math. Soc. Bull. No. 36 (1996), 3445.

[6] (with S. Shelah) Categoricity of theories in $L_{\kappa \omega}$, when $\kappa$ is a measurable cardinal. I. Fund. Math. 151 (1996), no. 3, 209240.

[7] Toronto spaces, minimality, and a theorem of Sierpiski. Irish Math. Soc. Bull. No. 38 (1997), 5365.

[8] The Baer-Specker group. Irish Math. Soc. Bull. No. 40 (1998), 923.

[9] (with S.Shelah) A result related to the problem CN of Fremlin. J. Appl. Anal. 4 (1998), no. 2, 161165.

[10] (with S. Shelah) Almost disjoint pure subgroups of the BaerSpecker group. Abelian groups and modules (Dublin, 1998), 225230, Trends Math., Birkhuser, Basel, 1999.

[11] Almost disjoint families: an application to linear algebra. Electron. J. Linear Algebra 7 (2000), 4152. 
[12] (with S. Shelah) Infinitary axiomatizability of slender and cotorsion-free groups. Bull. Belg. Math. Soc. Simon Stevin 7 (2000), no. 4, 623629.

[13] Transfer principles for generalized interval systems, Perspectives of New Music, 42 (2004), 150-190.

[14] (with B. Goldsmith) On cosmall abelian groups. J. Algebra 317 (2007), no. 2, 510518.

[15] Strong subgroup chains and the Baer-Specker group. Models, modules and abelian groups, 187198, Walter de Gruyter, Berlin, 2008 .

[16] (with R. Göbel and B. Goldsmith) On modules which are self-slender. Houston J. Math. 35 (2009), no. 3, 725736.

[17] A note on omitting types in propositional logic. Armen. J. Math. 7 (2015), no. 1, 15.

[18] (with B. Wald) $M$-slenderness, to appear in Israel J. Math.

Brendan Goldsmith (DIT).

E-mail address: brendan.goldsmith@dit.ie 